\title{
HYPOXAEMIA AFTER SURGERY AND ANAESTHESIA
}

\author{
J. P. Payne, M.B., F.F.A.R.C.S., D.A. \\ C. M. Conway, M.B., F.F.A.R.C.S., D.A. \\ Research Department of Anaesthetics, Royal College of Surgeons \\ of England, Lincoln's Inn Fields, London, W.C.2
}

THE significance of even transient anoxia during anaesthesia has been widely recognised for many years but until recently the frequent occurrence and potential danger of minor degrees of prolonged oxygen desaluration during the immediate post-operative period had not been appreciated. In 1962 however Nunn and Payne making use of the newer techniques of blood gas analysis demonstrated that some degree of arterial desaturation commonly occurred after even the most trivial surgical procedures under general anaesthesia. Since then post-operative hypoxaemia has been intensively investigated and though the problem is not solved some of the relevant factors have been more clearly identified.

It has of course been widely known since the work of Maier and Cournand in 1943 that lung surgery is associated with a substantial reduction in arterial saturation which persists for several days and even weeks after surgery, an observation later confirmed by Bjork and Hillty (1954) who drew attention to the significance of post-operative hypoxaemia in relation to the managemen't of patients after open-chest surgery. Three years earlier Troell (1951) had observed that major abdominal surgery was often followed by arterial desaturation both in patients who had breathed spontaneously and in those who had been artificially ventilated. In 1958 Gordh, Linderholm and Norlander who were the first workers in this field to use an oxygen electrode to determine oxygen tensions in blood obtained a mean fall in arterial oxygen tension of about $16 \mathrm{~mm} . \mathrm{Hg}$. after major non-thoracic surgery in patients free from cardiovascular and respiratory disease.

\section{Diagnosis of Postoperative Hypoxaemia}

One of the problems of post-operative hypoxaemia is the difficulty of diagnosis. For many years it was widely believed that the colour of the patient's skin would give the first indication of oxygen lack but even with an adequate skin blood flow the arterial oxygen tension can fall to as low as $40 \mathrm{~mm}$.Hg. without evidence of cyanosis (Nunn, 1966). In fact obvious clinical signs are absent with minor $\frac{\widehat{\Phi}}{\overparen{2}}$ degrees of post-operative hypoxaemia and art-ڤ erial oxygen saturation values show only $\mathrm{a}_{\odot}$ slight fall below normal. But this observation:is less re-assuring than is sometimes supposed. $\vec{\omega}$ Because of the characteristic shape of the? haemoglobin oxygen dissociation curve slighto

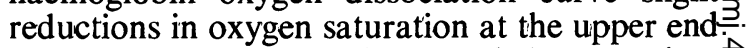
of the curve correspond to much larger reduc- $+\stackrel{+}{N}$ tions in arterial oxygen tension; (Fig. 1). Thus an oxygen saturation of $90 \%$ has an equivalent tension of no more than $60 \mathrm{~mm} . \mathrm{Hg} . \stackrel{\oplus}{ \pm}$ in otherwise normal arterial blood. This ex-응 plains why the measurement of arterial oxygen? tension provides a much more sensitive index $\vec{c}$ of minor degrees of arterial hypoxaemia than does the measurement of saturation.

Oxygen tension measurements are usualgy $\vec{\bullet}$ made by a polarographic technique which is chemical method of analysis based on the fastt? that when an inert metal such as gold, mercufy or platinum is negatively charged and immersed in an electrolyte it will give up electrons to dissolved oxygen. The transfer of electrons is $\stackrel{\varnothing}{\varnothing}$ proportional to the current flowing which in $\overrightarrow{\vec{B}}$ turn is dependent on the amount of oxygen $\frac{3}{3}$ present. The resultant current change is measured and expressed in terms of oxygen? tension.

The first measurements of oxygen tension in blood by polarography were carried out with a $\frac{\dot{\sigma}}{3}$ dropping mercury electrode such as that used by Gordh and his colleagues (1958) but this proved both tedious and difficult to use. In particular the deposition of plasma proteins 음 on the surface of the electrodes was a major $>$ source of trouble. However by 1956 Clark had demonstrated that it was possible to separate $\tilde{O}_{\text {S }}$ the entire electric cell from the blood or tissue by means of a thin polyethylene membrane 0 which prevented the passage of electrolytes but $\omega$ remained permeable to oxygen. This discovery completely revolutionised the design of oxygen electrodes so that today virtually all commer- $\$$ cially produced electrodes are based on Clark's ${ }_{+}^{+}$ original description.

To the improved methods of analysis must $\frac{\overrightarrow{0}}{\vec{D}}$ be added the more sophisticated techniques $\frac{\sim}{\mathbb{Q}}$ 


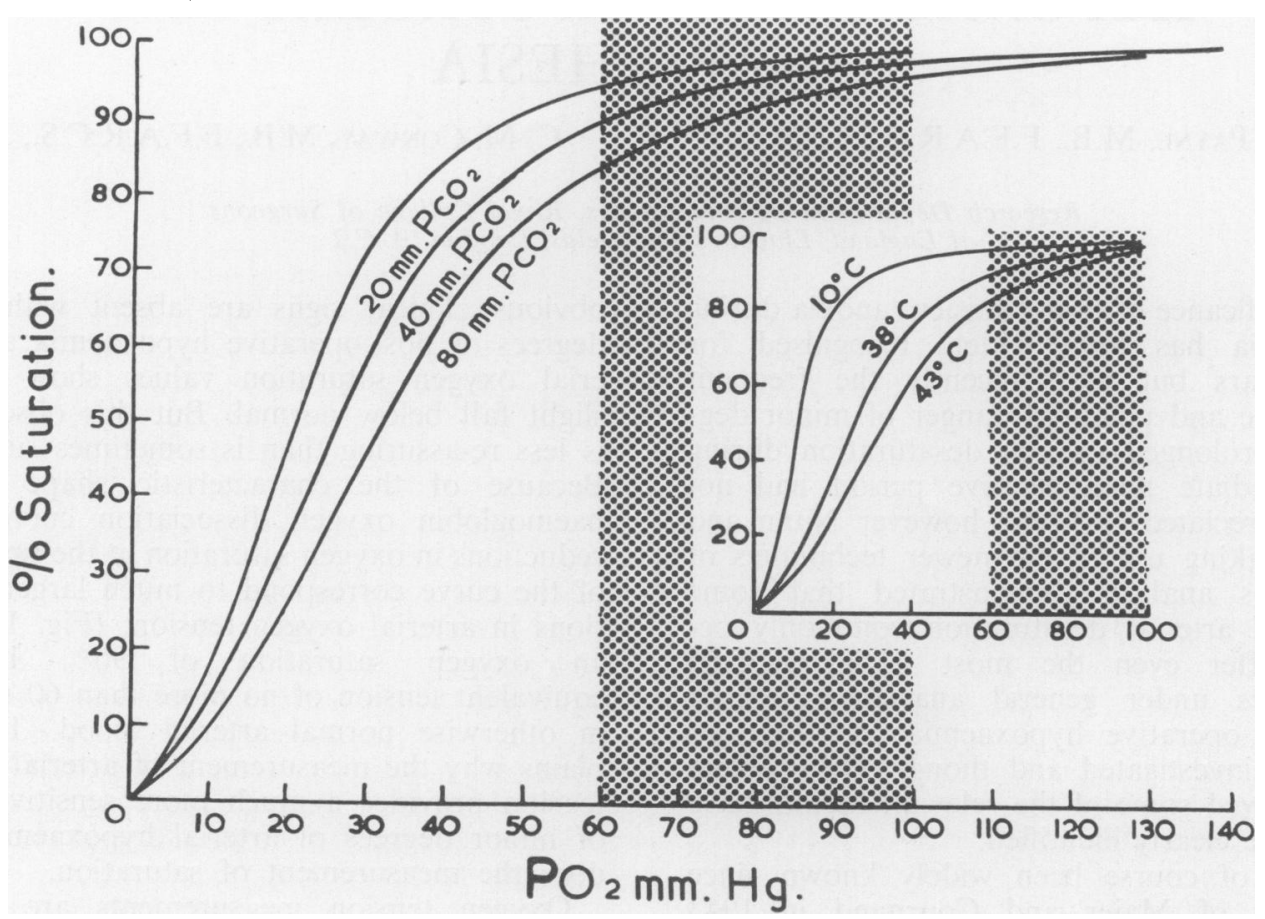

Fig. 1.-The relationship between oxygen tension and saturation showing the influence of temperature and carbon dioxide on the slope of the dissociation curve (modified from Samson Wright's Applied Physiology, p. 168, 11th Ed.).

for collecting arterial blood. In particular the developmentt within recent years of a percutaneous technique for catheterising small arteries such as the radial has made possible serial studies of blood gas changes during surgery and anaesthesia. The fact that both the electrode design and the technique of arterial catheterisation are recent developments explains why the detailed study of changes in arterial oxygen tension under different clinical conditions has only just begun.

\section{Mechanism of Postoperative Hypoxaemia}

In the original series of Nunn and Payne (1962) 24 patients who had breathed spontaneously during anaesthesia for a variety of relatively minor surgical procedures were found to be hypoxic for up to 48 hours after the end of the anaesthetic. In these patients the mean arterial oxygen saturation was $89 \%$ which corresponds to a mean oxygen tension of slightly less than $60 \mathrm{~mm} . \mathrm{Hg}$. In contrast the mean carbon dioxide tension was virtually normal within 20 minutes of the anaesthetic being discontinued. This suggested that under-ventilation was not a factor in the development of post-operative hypoxaemia and the belief that depression of respiration did not contribute to arterial oxygen desaturation was supported by Conway and Payne (1963) who found no evidence of under-ventilation while observing the effect of administering oxygen-enriched mixtures to hypoxaemic patients in the immediate pust-operative period. Twelve patients who were studied while breathing room air between one and two hours after the end of operation showed an immediate improvement in arterial saturation when exposed to an inspired mixture containing $30 \%$ oxygen. Increasing the inspired mixture to $50 \%$ oxygen did not materially affect the improvement which was not sustained when the oxygen-enriched mixtures were withdrawn. Throughout the study the arterial carbon dioxide tensions remained within normal limits but the extent of the desaturation varied over a fairly wide range and was not obviously related to the anaesthetic technique, the duration of the anaesthetic nor to the nature of the surgery.

Since, on the evidence, under-ventilation had not contributed to the arterial desaturation, consideration had to be given to other factors 
capable of interfering with oxygen transfer in the lungs of relatively normal individuals. Of these reduced oxygen diffusing capacity, though important in heavy exercise at altitude (West, Lahiri, Gill, Milledge, Pugh, and Ward, 1962), does not cause a fall in oxygen saturation at rest and therefore could be disregarded. This left only two major possibilities, pulmonary shunts and maldistribution within the lungs. The calculated shunt in the study of Nunn and Payne (1962) was approximately $25 \%$ of the pulmonary blood flow. The only known cause for such a large symptomless shunt is pulmonary collapse but no radiological evidence of frank atelectasis was obtained in any of these patients. Furthermore the fact that in such patients arterial oxygen saturation returned almost to normal on exposure to only moderately enriched mixtures virtually excluded shunting as the cause of the desaturation. Thus maldistribution or relative under-ventilation in a large proportion of the alveoli was left as the most likely explanation for the observed hypoxaemia.

The fact that patients on controlled respiration had not been included in these studies led to speculation that artificial ventilation might prevent the development of post-operative hypoxaemia but work by Bendixen, Hedley-White and Laver (1963) and Conway and Payne (1964) demonstrated that impaired oxygenation occurred in surgical patients just as readily after controlled ventilation under general anaesthesia as after spontaneous breathing during the anaesthetic.

In the series of Bendixen and his colleagues 18 patients free from known pulmonary disease were studied while undergoing operations which required profound muscular relaxation and controlled ventilation. $A$ mean fall in oxygen tension of $22 \%$ and a decrease in lung compliance of $15 \%$ were demonstrated over a period of study averaging 76 minutes during whioh ventilation was maintained at a constant level. At the end of the period of constant ventilation three successive hyperinflations of the lungs restored both arterial oxygen tension and lung compliance to control values.

Bendixen and his colleagues indicated that the progressive fall in lung compliance could be caused partly by changes in surface tension in the lungs but suggested that most of the decrease in compliance was due to the collapse of air spaces. The fact that the trend towards impaired oxygenation and reduced lung compliance was reversed by periodic hyperinfla- tion was used to support the argument that the arterial desaturation was due to pulmonarys collapse since it is well known that highero pressures are needed to open completely col-. lapsed air spaces than to further inflate partially ventillated alveoli.

The impaired oxygenation of the arteriale blood was attributed to capillary blood flow being maintained through collapsed and there $\frac{\widehat{T}}{\widehat{T}}$ fore unventilated segments of lung. This per- 0 fusion of underventilated alveoli was thoughtis to divert part of the pulmonary blood flow into the systemic circulation without participation in the normal ventilation processes of thew lung. Normally less than $5 \%$ of the total cardiaco output is shunted in this way but the develop-0 ment of atelectasis can lead to a variable but. often significant increase in the total shunt as 0 reflected in a substantial fall in arterial oxygen tension.

On the basis of their observations Bendixen $\stackrel{\oplus}{\oplus}$ and his group postulated that progressive pul-o monary atelectasis associated with impaired oxygenation of the arterial blood regularlyc accompanies anaesthesia if periodic hyperinflation of the lungs does not occur even when. ventilation is normal by the usual criteria. $\triangle \mathscr{\odot}$

The validity of this interpretation is douts ful however. It does not explain the observations of Conway and Payne (1964) who also investis igated the relation'ship between artificialo ventilation during surgery and post-operative oxygen desaturation in a group of 15 patients $\stackrel{\mathbb{D}}{\circ}$ anaesthetised for routine elective surgery. In $\overrightarrow{\vec{O}}$ this study the patients were anaesthetised with 3 a nitrous oxide-relaxant technique and ventilated $\supset$ manually so that the ventilation although? adequate, was unlikely to be uniform, a facto which was confirmed by the variations in the 3 . carbon dioxide tensions of the arterial blood $\frac{3}{3}$ (Fig. 2.)

Despite the irregular hyperventillation Conwayo and Payne observed a mean arterial oxygen saturation after sungery of only $91.2 \%$, equiva-은 lent to an oxygen tension of $68 \mathrm{~mm} . \mathrm{Hg}$. But not only was hypoxaemia present postoperatively, it was also in evidence during $\tilde{N}^{\circ}$ surgery even when hyperventilation was employed and in spite of an inspired oxygen concentration in the anaesthetic mixture, which $\omega$ was never reduced below $25 \%$. Most surprising of all however was the observation that some degree of desaturation was present in five premedicated patients studied before the in -+ duction of anaesthesia.

This unexpected observation gave support $\frac{\overrightarrow{0}}{\mathrm{D}}$ to the view that neither the anaesthetic agent $\frac{\stackrel{?}{\oplus}}{\circ}$ 

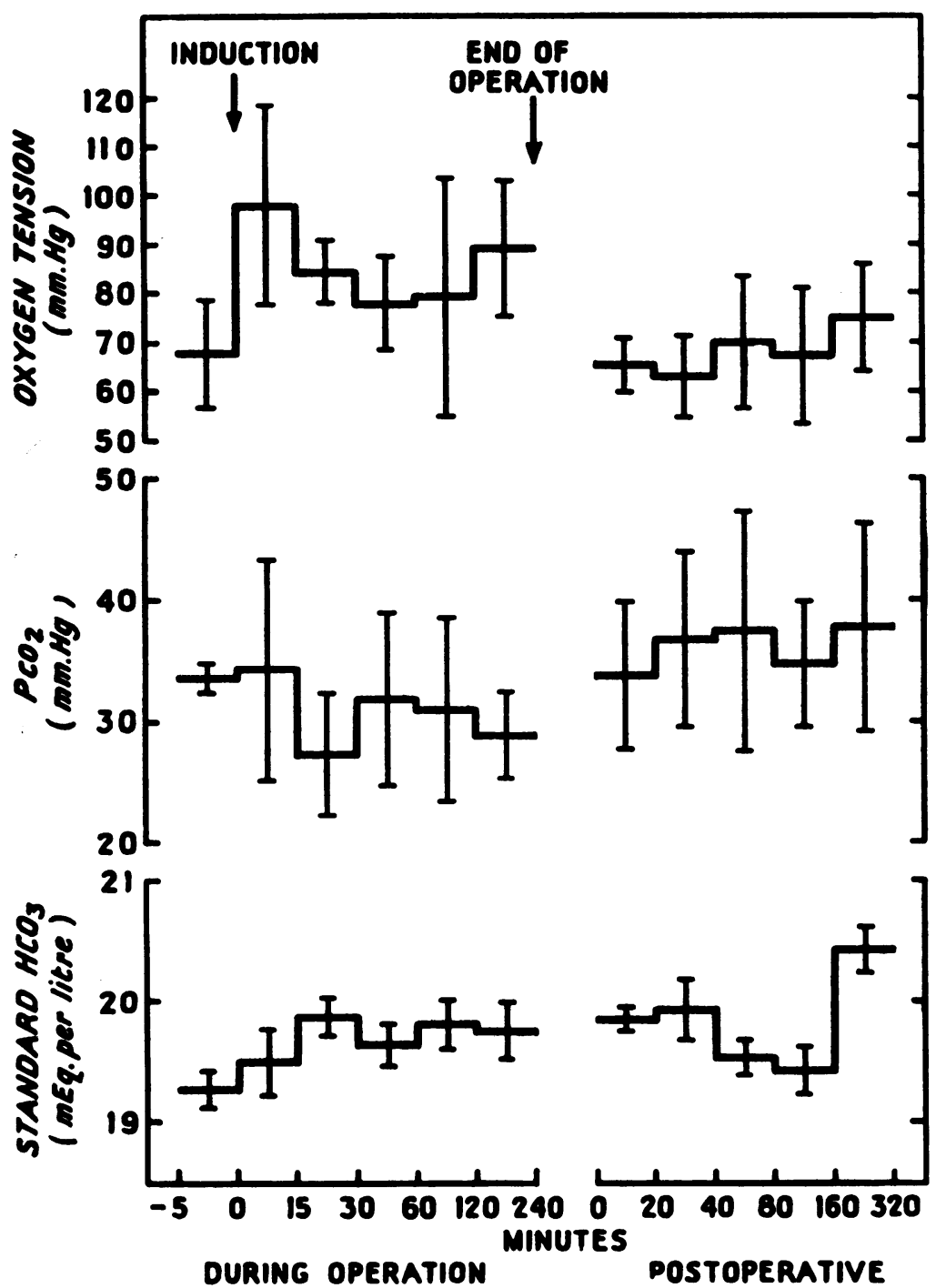

FIG. 2.-Changes in arterial oxygen tension, arterial carbon dioxide tension and standard bicarbonate before, during and after anaesthesia with controlled respiration. Horizontal lines denote mean values and vertical bars indicate standard deviations. Time scale is logarithmic. (By courtesy of the Editor of the Lancet).

nor the technique was solely responsible for the hypoxaemia and focused attention on premedication. Thus a more careful scrutiny of earlier papers revealed that oxygen desaturation after premedication was not uncommon, although in most instances the observation had been reported without comment (Tomlin, Conway and Payne, 1964).

\section{Effect of Premedication}

The first evidence of impaired arterial oxygenation after premedication was published in 1951 by Johnson who described a fall in oxygen saturation from 9.5 to $92 \%$ in nine patients given morphine and hyoscine before surgery. About the same time Troell (1951) reported a mean oxygen saturation value of $92.8 \%$ in 28 patients prepared for surgery; unfortunately the premedication was not stated. A further study in which the premedication was unspecified was that of Holiday, Ma and Papper (1957) who found a mean oxygen saturation of $83 \%$ in a group of 25 patients before surgery. Although these authors themselves expressed doubt about the accuracy of their method of determining oxygen saturation, the $10 \%$ error which they were willing to concede still implied 
a significant degree of hypoxaemia in their patients.

Further evidence of impaired arterial oxygenation after premedication is to be found in the work of Gordh, Linderholm and Norlander (1958) whose patients showed a significant fall in arterial oxygen tension after the injection of morphine and hyoscine. In the course of their investigations Gordh and his colleagues administered pure oxygen to premedicated patients and demonstrated a substantial increase in the alveolar-arterial oxygen gradient. This increased venous-admixture following premedication was attributed to bedrest and possibly to pre-existent pulmonary disease.

Other evidence of arterial oxygen desaturation in premedicated patients before surgery was obtained from a series of papers published between 1959 and 1962 by Dobkin and his group who measured the arterial oxygen saturation in a total of 161 premedicated patients before the induction of anaesthesia (Dobkin, 1959; Dobkin, Drummond and Perkin, 1959; Dobkin, Johnston and Skinner, 1959; Dobkin and Byles, 1962a, 1962b; Dobkin and Song, 1962). The mean arterial oxygen saturation of 90.7\% derived from these determinations implied a significant degree of impaired oxygenation ascribed by Dobkin and his colleagues to the central depressant effect of the narcotic drugs included in the premedication.

But the post-operative hypoxaemia observed by Conway and Payne (1964) occurred in patients given atropine only and therefore could not be attributed to narcotic drugs. The possibility that atropine could influence the oxygen content of arterial blood had then to be considered. Aocordingly Tomlin, Conway and Payne (1964) compared the mean arterial oxygen saturation of 24 patients given atropine with that of a similar unpremedicated group. The mean arterial oxygen saturation in the atropinised group was $93.4 \%$, a value significantly lower than the value of $96 \%$ obtained from the control group. When the saturation values were interpolated to obtain the corresponding oxygen tensions the atropinised patients were shown to have a mean arterial oxygen tension $15 \mathrm{~mm} . \mathrm{Hg}$. lower than that in the control group.

Other investigators however have failed to confirm this observation. Daly, Ross and Behnke (1963) found no change in arterial oxygen saturation ten minutes after intravenous atropine and Nunn and Bergman (1964) were unable to find a significant change in arterial oxygen tension twenty minutes after the drug had been given intravenously; but both thesez groups demonstrated a marked increase in phy- $\mathbb{\Phi}$ siological and anatomical dead space in their. healthy volunteers after the administration of $\Rightarrow$ atropine. Similarly in a limited study of six healthy young women admitted to hospital for uterine curettage Taylor, Scott and Donald $\overline{\bar{N}}$ (1964) showed that the arterial oxygen tension? was not significantly altered by the administration of atropine given intramuscularly. Because of the apparent discrepancies Conway and $\vec{\circ}$ his colleagues planned to extend their work toascertain firstly whether the action of atropine $\vec{\omega}$ was dependent upon the route of administra-o tion of the drug and secondly whether thes omission of atropine premedication would subs tantially modify the course of post-operative? hypoxaemia (Conway, 1966).

\section{Arterial Oxygen Tension in Normal Patients}

One difficulty that had to be overcomeo before such an investigation could be carried out ${ }_{-}$ was the lack of agreement among clinicianse about the normal arterial oxygen tension in hospitalised patients awaiting surgery. Indeed ${ }^{\infty}$ it was argued by Stephen and Talton (1968) that the real values were unknown. These? workers in a study of 14 surgical patien obtained the low mean value of $80.4 \mathrm{~mm}$. H and Hamilton and his colleagues (1964) derived an even lower value of $76.5 \mathrm{~mm}$. Hg. fromळ̋ 27 patients awaiting elective surgery.

To establish normal values for this parameter $\overrightarrow{\vec{B}}$ arterial blood gas tensions were determined in 3 a series of patients admitted to hospital for? elective surgery. For the purpose of this study? patients suffering from any form of cardiovasc-o lar or respiratory disease were excluded since 3 . the presence of such disease would almost certainly impair the oxygenation of arteriat. blood. Apart from this assessment of physicalo status patients were selected for the trial at ${ }^{2}$ random. Duplicate determinations of arterialo oxygen and carbon dioxide tensions were made in 70 adult patients of both sexes. No differ-․․․ ence in arterial oxygen tension was noted between the sexes, but there was a marked inverse correlation between arterial oxygeris tension and age. Statistical evaluation of this $\omega$ relationship gave a regression equation of the form $\mathrm{PaO}_{2}=102.5-0.22$ (age), (Fig. 3) with a standard deviation of $4.7 \mathrm{~mm} . \mathrm{Hg}$. , and a cor- $-\mathbb{\Phi}^{\mathbb{D}}$ relation coefficient, $r=-0.61$ (Conway, Payne and Tomlin, 1965). This relationship is substantially the same as that described by Raine $\frac{}{0}$ and Bishop (1963) who derived a regression $\frac{\text { }}{0}$ 


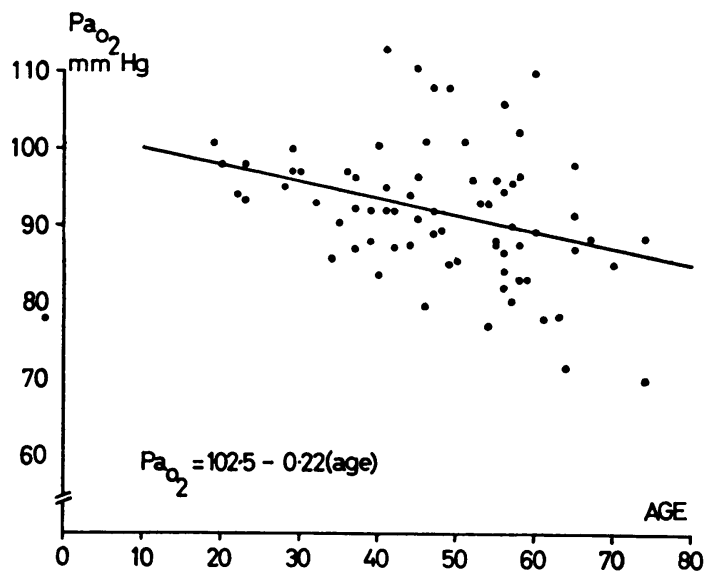

Fig. 3.-Arterial oxygen tension in relation to age. The points represent duplicate estimations of arterial oxygen tension in 70 adult patients. The regression line and the formula from which it was derived are shown. (By courtesy of the Editor of the British Journal of Anaesthesia.)

equation of $\mathrm{PaO}_{2}=103.7-0.24$ (age) from studies on healthy volunteers. It was therefore concluded that the arterial oxygen tensions of otherwise healthy surgical patients differed in no way from those of the normal population and that no special precautions were needed in a further study of the effects of atropine.

\section{Arterial Oxygen Tension and Atropine}

Studies were carried out on three separate and comparable groups of patients, all of whom received a standard dose of $0.6 \mathrm{mg}$. of atropine, regardless of weight. The first group of 18 patients received 'subcutaneous atropine, and in this group a mean fall in arterial oxygen tension of $8.9 \mathrm{~mm} . \mathrm{Hg}$. was observed one hour later. In the second group of 15 patients, who received intramuscular atropine the mean fall in oxygen tension was only $2.1 \mathrm{~mm}$. $\mathrm{Hg}$. and in the last group of 10 patients given intravenous atropine the fall in oxygen tension of 0.2 $\mathrm{mm}$. Hg. was negligible. Thus of the three groups, only those patients given subcutaneous atropine developed a significan't fall in arterial oxygen tension. The failure of Daly and his co-workers (1963) and Nunn and Bergman (1964) to demonstrate hypoxaemia after atropine can therefore be ascribed to the use of intravenous atropine in their studies.

This fall in arterial oxygen tension after atropine is less than that previously reported by Tomlin, Conway and Payne (1964). This may be due to the fact that in the earlier study separate treated and control groups were com- pared whereas in the present study each patien't acted as his own control. Furthermore in the original study two other potential sources of error were present: first, many of the oxygen tension values were derived from oxygen saturation measurements by means of the Dill dissociation curve, and second the mean carbon dioxide tension in these patients was $8 \mathrm{~mm} . \mathrm{Hg}$. below the generally accepted normal of 40 $\mathrm{mm} . \mathrm{Hg}$. This respiratory alkalosis, by shifting the dissociation curve to the left may have exaggerated the fall in oxygen tension and added to the error inherent in saturation determinations.

The modifying influence of atropine upon pulmonary function is not in dispute. Higgins and Means in 1915 demonstrated that the respiratory dead space in man was increased after the parenteral administration of atropine, an observation since confirmed by Severinghaus and Stupfel (1955); Daly, Ross and Behnke (1963) and Nunn and Bergman (1964). Severinghaus and Stupfel related the increased dead space to reduction in bronchial and tracheal tone produced by atropine. In a more detailed study Daly and his co-workers showed that after atropine in man an increase in lung compliance occurred which was independent of a simultaneously occurring fall in airway resistance. They were also able to demonstrate a reduction in pulmonary vascular resistance and a movement of blood out of the lungs which reduced the quantity available for gas exchange. Both these effects could be explained by a specific action of atropine upon the pulmonary vasculature.

A displacement of blood from the lung by atropine was also invoked by Rotman (1964) to account for a reduction in pulmonary diffusing capacity produced by atropine which could not be adequately explained on the basis of the increased respiratory dead space. Further support for the view that blood is displaced from the lungs into the systemic circulation by atropine comes from the observation that in anaesthetised patients with hypotension and bradycardia the intravenous injection of atropine is followed within 20 seconds by a rise in blood pressure which precedes the onset of tachycardia (Payne, 1966).

Another aspect of the rather complex action of atropine on the lungs was investigated in sheep by Halmagyi and his colleagues (1964) who studied the relationship between lung compliance and effective pulmonary capillary blood flow before and after the administration of atropine. On the basis of their findings they 
postulated the existence of a local pulmonary alveolar vascular reflex by which perfusion is regulated in response to ventilation. They further postulated that atropine blocks this local reflex and renders the pulmonary blood flow passive.

Thus the fall in arterial oxygen tension following the subcutaneous administration of atropine could be due to its action on the nervous or local reflex regulation of the circulation through the lung; but it could also result from impaired ventilation due to increased tenacity of secretions following atropine. The fact that the fall in oxygen tension appears to be a function of the route of administration supports the latter explanation. This phenomenon could not be demonstrated when atropine was given by intravenous injection which favours rapid absorption, a high initial blood level, and a relatively short duration of action. Subcutaneous administration allows slow absorption and the possibility of prolonged maintenance of effective blood levels. In this connection it has long been recognised that the subjective effects of atropine are minimal when given intravenously and most pronounced after subcutaneous administration.

The circulatory and ventilatory effects of atropine on the lung are difficult to reconcile particularly in relation to the effects on arterial oxygen tension. Nevertheless there is sufficient evidence that the drug is implicated in the development of post-operative hypoxaemia to justify the recommendation that it should no longer be used routinely for premedication.

\section{Postoperative Hypoxaemia and Age}

Recently Nunn (1965) has demonstrated a significant correlation between the severity of of post-operative hypoxaemia and age, and has drawn attention to the existence of a similar relationship in previous published series by other authors. Such a relationship between age and arterial oxygen tension during the postoperative period might of course have been anticipated from the work of Raine and Bishop (1963) which related arterial oxygen tension to age in normal subjects. Of considerable importance is the fact that the slope of the arterial oxygen tension-age regression line is much steeper in patients after surgery than in normal volunteers (Raine and Bishop, 1963) or in healthy patients awaiting surgery (Conway, Payne and Tomlin, 1965). The increased slope of this line in the post-operative period implies that a greater fall in arterial oxygen tension is to be expected in elderly patients

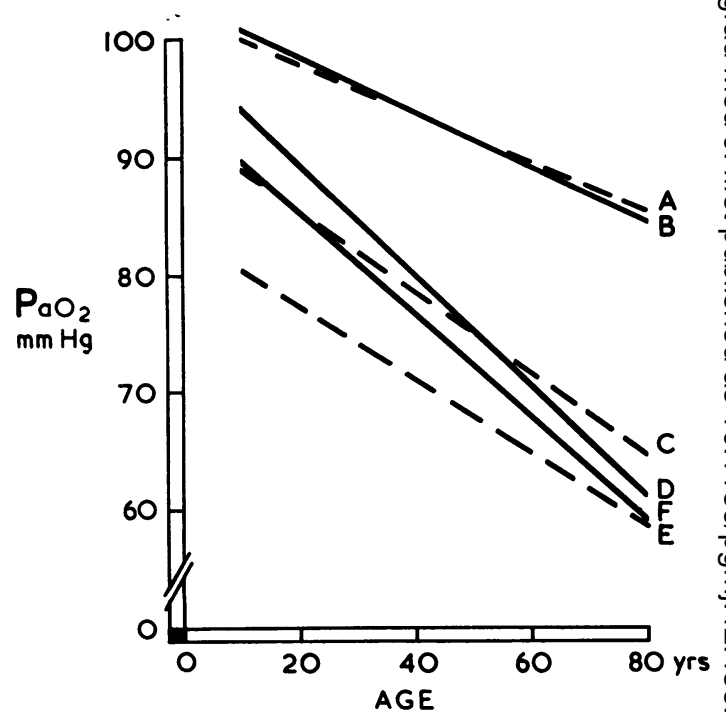

FiG. 4.-
A. Conway, Payne and Tomlin (1965) conscious surgical patients
B. Raine and Bishop (1963) healthy volunteers
$102.5-0.22$ (age)
C. Gordh, Linderholm and Norlander (1958)
E. Nunn (1965) 1 hour after operation
103.7-0.24 (age)
92.1-0.327 (agి
84.8-0.343 (a产)
D. Palmer and Gardiner (1964)
day after operation

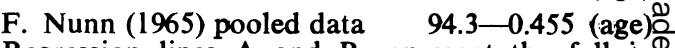 Regression lines $A$ and $B$ represent the fall in oxygen tension with age in healthy subjects. $\mathrm{Re}-\vec{F}$ gression lines $C, D, E$ and $F$ represent the fallo in oxygen tension with age in patients after anaesthesia and surgery and indicate that not only is the oxygen tension lower after anaesthesia. and surgery but also that the fall is greater with increasing age.

(Fig. 4) whose arterial oxygen tension is alreadyo low and who are therefore least able to tolerate further impairment (Payne and Conway, 1965).

\section{Other Factors}

Although there is now considerable agree-D ment that the fundamental disorder in post operative hypoxaemia is a disturbance in the ventilation-perfusion ratio, other explanations for this phenomenon have been advanced.

In a review of the factors influencing post $\omega$ operative hypoxaemia Marshall and Millaर̃ (1965) claimed that the hypoxaemia which theye observed could be explained almost entirely by a combination of under-ventilation and 'diffusion hypoxia' but their evidence is not convincing. The highest mean carbon dioxide tension recorded in their studies was $4 \frac{\text { P }}{\mathrm{P}}$ 
mm.Hg., a level scarcely compatible with significant under-ventilation. The occurrence of 'diffusion hypoxia' following the return to airbreathing after inhaling nitrous oxide is of course well known (Fink, 1955). It is due to the rapid passage of large volumes of nitrous oxide from the pulmonary capillary blood into the alveoli. Such a transfer of nitrous oxide dilutes the alveolar air and produces inspiratory hypoventilation with a tendency to expiratory hyperventilation. The phenomenon however is essentially transient and is unlikely to give rise to post-operative hypoxaemia lasting several hours.

In support of their contention Marshall and Millar pointed out that they had been unable to demonstrate post-operative hypoxaemia after short operations but that it was common after more prolonged procedures. They argued that during long operations more nitrous oxide is taken up and as a result a greater amount of the gas is available to cause diffusion hypoxia when the anaesthetic is withdrawn. But nitrous oxide is a relatively insoluble anaesthetic gas with a high rate of uptake only during the induction stage; thereafter the uptake falls off very rapidly so that the amount dissolved in the body when anaesthesia is prolonged is not substantially increased. This, together with the fact that impaired oxygenation is commonly found post-operatively in patients who have not been exposed to nitrous oxide, virtually excludes diffusion hypoxia as a major factor in the development of post-operative hypoxaemia.

Nunn and his colleagues (1965) have described another possible factor in the genesis of post-operative hypoxaemia. They showed that when volunteers breathed within their functional residual capacity by deliberately contracting the abdominal muscles during expiration increased shunting of blood occurred in the lungs. Nunn and his colleagues also showed that the shunting effect was increased by breathing pure oxygen and that on return to air-breathing the oxygen tension fell sharply to below normal levels and was associated with a varying degree of lung collapse which persisted for up to 48 hours.

This observation may explain why patients straining on an endotracheal tube are often cyanosed even when the tidal volume is apparently normal. Presumably patients with chronic chest disease are particularly susceptible to this type of collapse and this probably accounts for Hobsley's observations (1963) that if a reduced arterial oxygen tension was found immediately after operation in patients with chronic bronchitis frank collapse almost invariably followed.

In addition to chronic chest disease a variety of other conditions such as obesity, abdominal surgery and relaxant drugs can reduce the functional residual capacity, and it is well within the bounds of possibility that this reduction can exaggerate or even provoke postoperative hypoxaemia. It is difficult however to see how 'such hypoxaemia could be symptomless; almost certainly in these circumstances the frank atelectasis described by Hobsley would develop and diagnosis would be relatively easy. It is worth remembering that the hypoxaemia described by Nunn and Payne (1962) was not associated with demonstrable atelectasis or indeed with any signs and symptoms other than the reduced oxygen 'tension in the blood, wherein lies the danger.

\section{Significance of Postoperative Hypoxaemia}

The clinical significance of post-operative hypoxaemia is not easy to assess. A reduction of arterial oxygen tension of 20 or even 30 $\mathrm{mm} . \mathrm{Hg}$. from the normal level is unlikely to result in dangerou's tissue hypoxia in healthy individuals at rest but such a reduction oocurring in patients whose arterial oxygen tension is already low might easily lead to serious hypoxia and even death. The danger is greatest in the immediate post-operative period when the restlessness of hypoxia is often misinterpreted as evidence of pain and treated with morphine. Patients with limited cardiac or respiratory reserves are particularly vulnerable as also are patients whose metabolism is increased or otherwise deranged, and the administration of oxygen should be a routine part of their post-operative management. Elderly patients who are liable to a greater degree of post-operative hypoxaemia superimposed upon pre-existing normally low arterial oxygen tensions should also receive such routine oxygen therapy.

The administration of oxygen does not solve the problem of post-operative oxygen deficiency but at least it relieves the hypoxia and in individual cases it may even prevent the onset of irreversible brain damage. Recently however Ravin (1966) has claimed that the impaired oxvgenation seen after surgery and anaesthesia will respond to deep breathing in nearly every instance. In his series 20 healthy patients were studied following surgery. One hour after operation arterial blood samples were withdrawn for the determination of oxygen saturation values, thereafter ten patien's selected at 
random were asked to take five consecutive deep breaths. The effect of this was to produce a mean arterial oxygen saturation that was significantly greater than in the control group; this difference remained significant after eight to ten hours. If Ravin's observations can be substantiated the management of postoperative hypoxaemia will be considerably simplified and perhaps a large element of the risk involved eliminated.

\section{REFERENCES}

Bendixen, H. H., Hedley-Whyte, J., and LAVer, M. B. (1963): Impaired Oxygenation in Surgical Patients during General Anesthesia with Controlled Ventilation. A Concept of Atelectasis, New Engl. J. Med., 269, 991 .

BJORK, O. V., and HilTY, H. J. (1954): The Arterial Oxygen and Carbon Dioxide Tensions during the Post-operative Period in Cases of Pulmonary Resections and Thoracoplasties, J. thorac. Surg., 27, 455.

Clark, L. C. (1956): Monitor and Control of Blood and Tissue Oxygen Tension, Trans. Soc. for art. Int. Organs, 2, 41.

Conway, C. M. (1966): Arterial Oxygen Tensions in Surgical Patients. In: Oxygen Measurements in Blood and Tissues and their Significance. p.173. Ed. J. P. Payne and D. W. Hill. London: J. A. Churchill.

Conway, C. M., and Payne, J. P. (1963): Postoperative Hypoxaemia and Oxygen Therapy, Brit. med. J., i, 844.

ConWAy, C. M., and PAYNe, J. P. (1964): Hypoxaemia Associated with Anaesthesia and Controlled Respiration, Lancet, i, 12.

Conway, C. M., Payne, J. P., and Tomlin, P. J. (1965): Arterial Oxygen Tensions of Patients awaiting Surgery, Brit. J. Anaesth., 37, 405.

DALY, W. J., Ross, J. C., and BeHNKe, R. H. (1963): The Effect of Changes in the Pulmonary Vascular Bed produced by Atropine, Pulmonary Engorgement and Positive-pressure Breathing on Diffusing and Mechanical Properties of the Lung, J. clin. Invest., 42, 1083.

DobkIN, A. B. (1959): The Effect of Fluothane on Acid-base Balance, Anesthesiology, 20, 10.

Dobkin, A. B., Drummond, K., and PURKIN, N. (1959): Anaesthesia with the Azeotropic Mixture of Halothane and Diethyl Ether, Brit. J. Anaesth., 31, 53.

Dobkin, A. B., Johnston, H. J., and Skinner, L. C. (1960): A Study of Chloroform Anaesthesia in a Precision System: I. The Effect on Anion-cation Balance in Man, Canad. Anaesth. Soc. J., 7, 257.

DOBKIN, A. B., and BYLES, P. H. (1962): Effect of Fluroxene (Fluoromar) on Acid-base Balance in Man, Acta anaesth. Scand., 6, 115.

DOBKIN, A. B., and BYLES, P. H. (1962): The Effect of Trichloroethylene-Nitrous Oxide Anaesthesia on Acid-base Balance in Man, Brit. J. Anaesth., 34, 797.

Dobkin, A. B., and Song, Y. (1962): The Effect of Methoxyflurane-Nitrous Oxide Anesthesia on Arterial $\mathbf{3 H}$, Oxygen Saturation, Paco, and Plasma Bicarbonate in Man, Anesthesiology, 23, 601 .

FINK, B. R. (1955): Diffusion Anoxia, Anesthesiology, 16, 511 .
Gordh, T., Linderholm, H., and Norlander, O. (1958): Pulmonary Function in Relation to Anes-을 thesia and Surgery Evaluated by Analysis of Oxygen Tension of Arterial Blood, Acta. Anaesth.@ Scand., 2, 15.

Halmagyi, D. F., Colebatch, H. J. H., Starzechi, B., and Horner, G. J. (1964): Pulmonary Alveolar-吕 Vascular Reflex, J. appl. Physiol., 19, 105.

Hamilton, W. K., MoDonald, J. S., Fischer, H. W., and Bethards, R. (1964): Post-operative Respira- $\overline{\bar{c}}$ tory Complications : a Comparison of Arterial Gas? Tensions, Radiographs and Physical Examination, $\mathbb{Q}$

Anesthesiology, 25, 607.
Higgins, H. L., and MeANS, J. H. (1915): The Effect of Certain Drugs on the Respiration and Gaseous Metabolism in Normal Human Subjects, J. Pharmacol. exp. Ther., 7, 1.

Hobsley, M. (1963): Respiratory Disturbances Caused by General Surgical Operations, Ann. roy Coll. Surg. Engl., 33, 105.

Holaday, D. A., MA, D., and PAPPER, E. M. (1957): The Immediate Effects of Respiratory Depression N on Acid-base Balance in Anaesthetised Man, J. $\frac{\vec{\infty}}{\infty}$ clin. Invest, 36, 1121.

JoHnson, S. R (1951): The Effect of Some Anaes-c thetic Agents on the Circulation in Man. With $\sharp$ Special Reference to the Significance of Pulmonaryo Blood Volume for the Circulatory Regulation, Acta. chir. Scand. Suppl., 158.

Maier, H. C., and Cournand, A. (1943): Studies of Arterial Oxygen Saturation in the Post-operative Period after Pulmonary Resection, Surgery, 13, 199. $\overrightarrow{-}$

Marshall, B. E., and Miller, R. A. (1965): Sorfe Factors Influencing Post-operative Hypoxaemig, Anaesthesia, 20, 408 .

NuNN, J. F. (1965): Influence of Age and Othe Factors on Hypoxaemia in the Post-operative Period, Lancet, ii, 466.

NunN, J. F. (1966): Alveolar-Arterial $\mathrm{Po}_{2}$ Difference in Anaesthesia. In : Oxygen Measurements in Blood $\bar{Q}$ and Tissues and their Signifioance. Ed. Payne, J. P., and Hill, D. W. p. 187. London: J. and A. Churchill.

NunN, J. P., and Bergman, N. A. (1964): The Effect of Atropine on Pulmonary Gas Exchange, Brit. J. Anaesth., 36, 68.

NunN, J. F., Coleman, A. J., Sachithanandan, T., $\frac{\bar{\partial}}{\partial}$ Bergman, N. A., and Laws, J. W. (1965): Hypoxaemia and Atelectasis Produced by Forced Expiration, Brit. J. Anaesth., 37, 3.

PAlmer, K. N., and Gardiner, A. J. (1964): Effect of Partial Gastrectomy on Pulmonary Physiology, Brit. med. J., i, 347.

PAYNe, J. P., and Conway, C. IM. (1965): Hypoxaemia after General Anaesthesia, Lancet, ii, 631.

PAYNe, J. P. (1966): In: Oxygen Measurements in Blood and Tissues and their Significance. Ed. Payne, $N$ J. P., and Hill, D. W. p.182. London: J. and A.尺 Churchill.

PAYNE, J. P., and CONWAY, C. M. (1965): Hypoxaemia in the Post-operative Period, Lancet, ii, 638.

RAINE, JunE, and BiSHOP, J. M. (1963): A Difference in $O_{\text {, Tension and Physiological Dead Space in }}$ Normal Man, J. appl. Physiol., 18, 284.

Ravin, M. B. (1966): Value of Deep Breaths in Reversing Post-operative Hypoxaemia, N.Y. State ${ }^{\text {? }}$ J. Med., 66, 244.

Rotman, H. H. (1964): Effect of Atropine on Pul- $\bar{O}$ monary Diffusing Capacity in Man, Brit. J. Anaesth., 36, 74. , 
Severinghaus, J. W., and S2\$6915, M. A. (1955): Respiratory Dead Space Increase Following Atropine in Man and Atropine, Vagal or Ganglionic Blockade and Hypothermia in Dogs, J. appl. Physiol., 8, 81.

StePHEN, C. B., and TAlToN, I. (1964): Immediate Post-operative Care, with Particular Reference to Blood-gas Studies, Canad. Anaesth. Soc. J., 11, 586.

TAYlOR, S. H., SCOTT, D. B., and DonalD, K. W. (1964): Respinatory Effects of General Anaesthesia, Lancet, i, 841 .
Tomlin, P. J., Conway, C. M., and Payne, J. P. (1964): Hypoxaemia Due to Atropine, Lancet, i, 14.

Troell, L. (1951): Post-operative Changes in Circulation and the Effects of Oxygen Therapy, Acta. chir. Scand., 102, 203.

West, J. B., Lahiri, S., Gill, M. B., Milledge, J. S., Pugh, L. G. C. E., and WARD, M. P. (1962): Arterial Oxygen Saturation During Exercise at High Altitude, J. appl. Physiol., 17, 617. 